\title{
Peer-to-Peer, Interactive GP Education can Reduce Barriers to Best Practice in Diabetes Management
}

\author{
Gary Deed (1) - Gary Kilov · Patrick Phillips · Anita Sharma • \\ Stephen Leow $\cdot$ Ian Arthur · John Barlow $\cdot$ Mark Kennedy
}

To view enhanced content go to www.diabetestherapy-open.com

Received: December 22, 2015 / Published online: February 18, 2016

(C) The Author(s) 2016. This article is published with open access at Springerlink.com

\begin{abstract}
Introduction: Perceived difficulties in initiating insulin in patients with type 2 diabetes (T2D) may prevent many general practitioners (GPs) from using insulin even when recommended in guidelines. This paper describes a Royal Australian College of General Practitioners accredited education program on starting insulin in T2D, and its impact on GPs' attitudes and behavior.
\end{abstract}

Electronic supplementary material The online version of this article (doi:10.1007/s13300-016-0156-0) contains supplementary material, which is available to authorized users.

\section{G. Deed $(\varangle)$}

Mediwell, Coorparoo, QLD, Australia

e-mail: g.deed@uqconnect.net

G. Kilov

Seaport Practice, Launceston, TAS, Australia

P. Phillips

Queen Elizabeth Specialist Centre, Adelaide, SA, Australia

A. Sharma

Platinum Medical Centre, Chermside, QLD, Australia
Methods: A faculty comprising GPs with diabetes expertise, Credentialed Diabetes Nurse Educators, and endocrinologist developed and implemented the education program. The program content was highly procedure focussed, emphasizing simple, best-practice processes for starting insulin therapy and focussing on multidisciplinary models of care. The highly interactive format of the workshops included peer-to-peer learning, in which education was led by diabetes-experienced GP educators, as well as case study-based approaches and small group discussions. GP attendees were asked to rate their individual confidence and attitudes at the beginning and end of the meeting. In addition, participants $(n=220)$ from two workshops in 2013 were sent a survey

\author{
S. Leow \\ University of Adelaide, Adelaide, SA, Australia \\ I. Arthur \\ Toormina and Sawtell Medical Centre, \\ Coffs Harbour, NSW, Australia \\ J. Barlow \\ Bankstown Medical Centre, Bankstown, NSW, \\ Australia \\ M. Kennedy \\ Corio Medical Clinic, Geelong, VIC, Australia
}


3 months after the meeting to gauge the longer-term impact on their clinical practice.

Results: Since 2008, more than 2500 GPs have attended the workshops, and report substantial improvements in confidence; after attending, more GPs were willing to start insulin within their practice. Evaluations at 3 months post-meeting indicate that the increased confidence was associated with behavioral changes in the subgroup evaluated at this time $(n=48)$. Success of this program was attributed to peer-to-peer education, multidisciplinary input, easily implemented best practice procedures and checklists for starting insulin, and constant adjustment of meeting process and content based on feedback and guideline changes.

Conclusion: A peer-to-peer, interactive GP education program reduced GPs' perceptions of the difficulties of starting insulin in T2D and achieved changes in attendees' clinical practice. This education program offers an effective approach to overcome the therapeutic inertia that is too common in diabetes management.

Keywords: Australia; Continuing medical education; General practitioners; Primary care; Insulin therapy; Type 2 diabetes mellitus

\section{INTRODUCTION}

Approximately 70,000 adult Australians develop type 2 diabetes (T2D) each year. With a limited number of diabetes clinics and endocrinologists, general practitioners (GPs) will increasingly need to manage T2D patients on insulin. On average, in a survey of Australian GP's, diabetes encounters comprised $67.4 \%$ of chronic health conditions managed [1]. However, many GPs are reluctant to prescribe insulin [2, 3], even though Australian guidelines highlight the need for it [4-6]. GPs perceive that starting insulin is difficult because of uncertainty about guidelines, lack of time and limited procedural guidance for managing the process [7].

Therapeutic inertia in the management of T2D among GPs is a major concern given the current and future burden of T2D in Australia $[8,9]$, and the importance of achieving glycemic targets for reducing complications [10]. Indeed, the National Diabetes Strategy and Action Plan includes education on insulin commencement as one of the key actions needed to achieve goals of preventing and reducing diabetes-related complications [11]. To address this need, an education program was developed for Australian GPs aimed at improving their knowledge, confidence and attitudes towards starting insulin. This article describes the development of the program, the format that contributes to its success and some recent research into the impact on GP behavior 3 months after the educational activity.

\section{METHODS}

\section{Program Development}

The program was initiated in 2008 by a number of the authors (GD, GK, PP, AS, SL, IA, JB, MK) in conjunction with the sponsor (SanofiSydney Australia). They then sought assistance from an accredited continuing medical education (CME) provider (Vivacity Health, Sydney Australia), who worked with a faculty of GPs with diabetes expertise, Credentialed Diabetes Nurse Educators (CDEs) and an endocrinologist to develop the content and format of the educational program. Using published evidence and their own experience, the faculty identified the key learning issues for 
GPs around starting insulin and the most appropriate learning techniques for education.

The content of the workshops focussed on multidisciplinary models of care, involving endocrinologists and local CDEs as well as GPs. A key barrier to GPs starting insulin therapy is a perception that it is a difficult process, requiring time and planning [3]. Therefore, the program was highly procedure focussed, reinforcing a simple, best-practice process for starting insulin that was both practical and easily implemented in the surgery, with or without the aid of a CDE/ practice nurse $[7,12]$. The program also reviewed situations that GPs were likely to come across once patients were established on insulin, such as sickness, weight gain, managing hypoglycemia and travel. Participant learning was reviewed with pre-workshop questions on diabetes and insulin management compared with an identical post-workshop survey for all participants, and as with the basis of this paper, sampling at 3 months in a smaller representative sample. It is beyond the scope of this article to describe the content fully, but it covered the range of lifestyle interventions and oral treatments available in Australia, while focussing on when and how to initiate insulin in T2D, including the appropriate use of basal and premixed insulin.

Key elements of the educational format were:

- Using peer-to-peer group learning The education was led by diabetes-experienced GP educators. This approach of using peers who 'either know more or know differently' is an established success factor in physician education [13]. In addition, learning with GP colleagues exposes people to variability in how issues are addressed, enabling self-reflection and providing support [12].

- Extending invitations to GPS interested and motivated to learn about insulin therapy A systematic review of interventions to change physician performance highlighted the importance of individuals' readiness to change as a determinant of effectiveness [14]. Therefore, a decision was made to invite GPs who were interested and motivated to learn about insulin therapy. Initially, these GPs were identified through feedback from the sponsor, but subsequent meetings have been subscribed to mainly through word-of-mouth.

- Interactive format The format was highly interactive, utilizing case study-based approaches, audience response systems, small group discussions, and question and answer sessions with the faculty. Common questions, when asked by attendees, such as "what is a safe starting dose of insulin? What time does a patient inject insulin? and If a patient travels overseas, what advice do I give?", were incorporated in workshops or addressed specifically at the Q\&A session incorporated within the workshop format.

The final meeting format is outlined in Fig. 1. The meetings were facilitated by the faculty, and attendees were split into groups of 25 (maximum) to optimize interactivity.

Content for this education initiative was developed by the faculty with the assistance of an accredited CME provider, and accredited with 40 Category 1 Royal Australian College of General Practitioners (RACGP) points. The sponsor had no input into the content of the program, but provided an unrestricted educational grant for the development of workshop materials, and provided funding for facility hire, faculty and attendees' transportation, accommodation, and meals in accordance with Australian regulations.

The first workshop was held in 2008. Since then, 41 workshops have been held throughout Australia, with over 2500 GP participants. The 


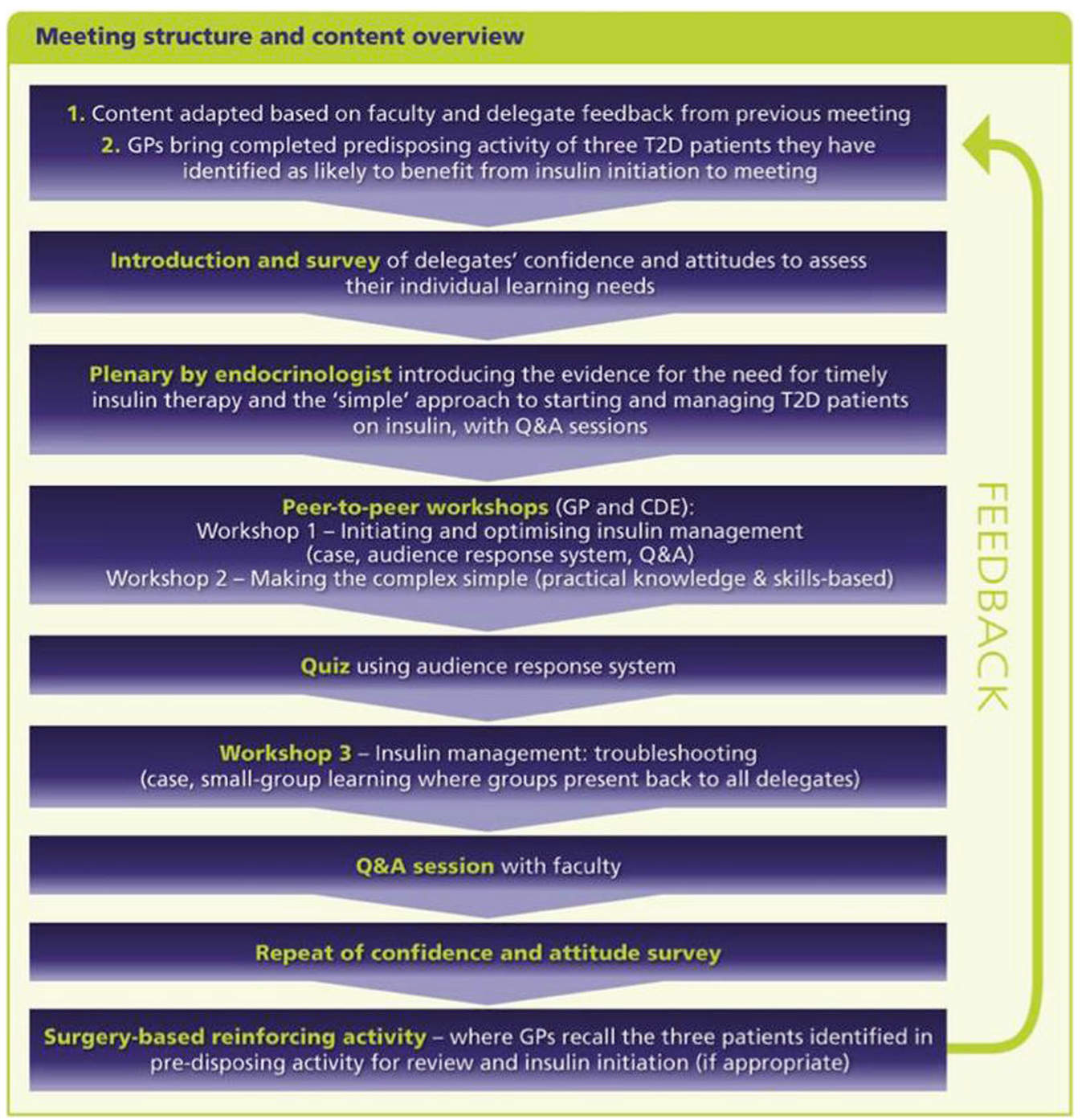

Fig. 1 Meeting structure and content overview. T2D type 2 diabetes, $G P$ general practitioner, $Q \& A$ question and answer, $C M E$ continuing medical education

attendance was open to any rural, regional as well as urban GPs who had identified an interest in insulin management.

\section{Facilitator Training and Ongoing Program Refinement}

GP attendees were asked to rate their individual confidence and attitudes at the beginning and end of the meeting, and to evaluate workshop content and format using an evaluation form.
Faculty members developed a training process to fine-tune both their delivery of the program and the meeting content. After each workshop, the faculty agreed on what needed to be incorporated or amended for the next meeting based on facilitator and participant feedback, and the publication of any new relevant evidence-based information. For example, based on attendee's feedback, changes to workshop structure included a substitution of a workshop on "Setting up a Diabetes Clinic" to 
workshops incorporating practical patient resources to facilitate discussion and implementation of physical activity and diet changes in diabetes.

\section{Compliance with Ethics Guidelines}

This article is based on previously conducted studies and does not involve any new studies of human or animal subjects performed by any of the authors. Permission was obtained from the de-identified survey participants.

\section{RESULTS}

\section{Measuring the Workshop's Success}

Data from pre- and post-meeting assessments from 2008 to the end of 2013 showed that GPs' confidence in starting and up-titrating insulin improved substantially as a result of the meeting $(n=1368)$. Fewer GPs needed to refer patients to an endocrinologist and more were willing to start insulin within their practice with help from CDEs (Fig. 2). However, it was not clear whether this immediate post-meeting

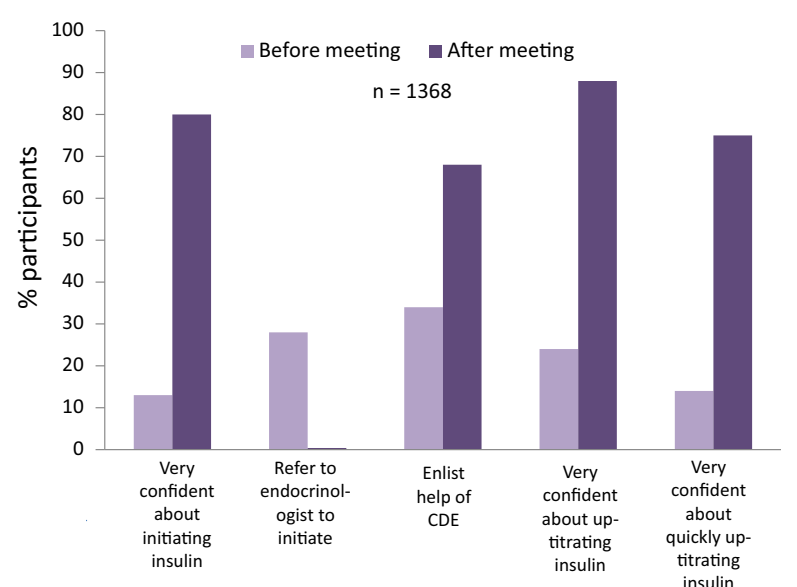

Fig. 2 Initiating and up-titrating insulin before and immediately after meeting survey results: aggregated data from the 1368 GP attendees. CME continuing medical education, GP general practitioner

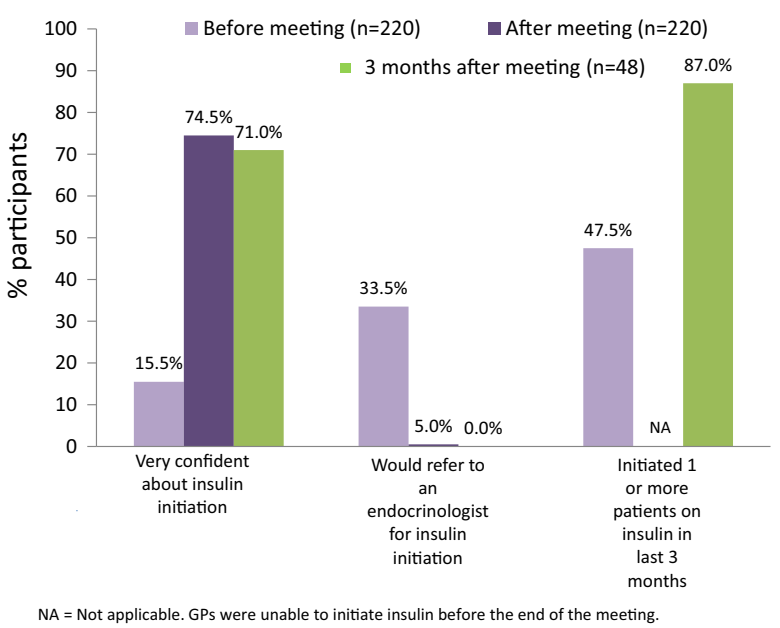

Fig. 3 3-month follow-up cohort: GP confidence, referral for initiation and actual insulin initiations before and after the meeting and 3-months post-meeting in patients with type 2 diabetes. $N / A$ not applicable because this question was not asked in the immediate post-meeting evaluation, GP general practitioner

confidence translated into practice improvements. Therefore, at the last two workshops in 2013, participants $(n=220)$ were also sent a survey 3 months after the meeting to gauge the impact of the education on their clinical practice. Overall, 48 participants returned completed survey forms $(21.8 \%$ response rate); these participants were representative in sex and area of practice (urban/rural) of the overall attendees.

Before the meetings, $73 \%$ of the 220 GPs surveyed had a negative perception of insulin therapy (e.g., too many barriers, can't manage patients' fears). This dropped to $9 \%$ after the meetings, with 91\% thinking that managing patients on insulin was not as hard as they had thought. This change in attitude persisted after 3 months, as did the improvement in GPs' confidence to address patient concerns, such as fear of injections. Moreover, a larger percentage of GPs reported starting one or more patients on insulin 3 months after versus 3 months before the meeting ( $87.0 \%$ vs $47.5 \%)$, 
suggesting that this improved confidence resulted in more initiations (Fig. 3).

\section{DISCUSSION}

Emerging evidence has supported use of "Local Opinion Leaders" and the use of interprofessional and peer-to peer education in enabling positive health educational programs [15-17]. This program achieved its objectives of reducing GPs' perceptions of the difficulties of starting insulin in T2D. Importantly, surveys conducted 3 months after the last two workshops in 2013 demonstrate that attendee confidence is maintained and results in a real change during clinical practice.

We believe the success of this program can be attributed to:

- Use of peer-to-peer learning methodology, which had a positive effect on interaction and freedom of discussion, and consequently on meeting outcomes.

- Choice of GP and CDE facilitators In our view, facilitators need to be experts in the subject and passionate about it, and good educators, but open to learning more themselves. Interestingly, the benefits of peer-to-peer learning applied as much to the faculty members as it did to the attendees: the faculty became more skilled at educating their peers, and their interest in diabetes grew. Many faculty members have since founded the RACGP diabetes special interest network together.

- Providing content that is easily applied during clinical practice Previous research has shown the importance of developing content that is useful for implementation by GPs in routine clinical practice. For example, two Canadian studies of multidisciplinary peer-to-peer education programs demonstrated success in increasing and maintaining GP confidence by including content that was 'useful and doable in real GP time' $[18,19]$.

- Reinforcing a multidisciplinary approach to diabetes management Many GPs who did not consider involving a CDE in starting patients on insulin before the meeting had altered their opinion by the end, which will help time-poor GPs to manage their patients on insulin. It also helped to clarify the roles of the various health professionals involved in managing T2D.

- Keeping the content relevant, interesting and up-to-date Having an efficient, workable process in place to refine both the content and its delivery that takes into account meeting feedback and changes to clinical practice is crucial to maintaining the relevance and quality of the program [20].

A key limitation of this analysis is that the impact of education on 3-month outcomes was only examined in recent cohorts of attendees, and only $21.8 \%$ of these attendees responded to the 3-month evaluation. While this response rate is somewhat disappointing, it is higher than the $16.3 \%$ rate reported in a recent study of responses to surveys among Australian GPs [21]. Since the 3-month evaluation will be conducted at all subsequent workshops, there is an opportunity to accumulate further data on the medium-term impact on attendee behavior, as well as to integrate initiatives to improve response rates to the 3 -month evaluation. The program did not aim to assess any long-term effects on GP practice or patient health outcomes.

\section{CONCLUSIONS}

This education program addressed an important need in Australian general practice-to educate 
GPs about starting insulin, and thereby overcome the therapeutic inertia that is too common in diabetes management. It was developed by a passionate multidisciplinary faculty who set out to deliver a program that would change GP behavior in relation to insulin initiation. The recent data collected 3 months post-workshop attest to its success in achieving this goal. Even after 7 years, each workshop continues to be fully subscribed to, and the faculty is committed to continuous improvement based on feedback and changes in evidence-based guidelines.

\section{ACKNOWLEDGMENTS}

Sanofi Australia has provided sponsorship to this program through an unrestricted educational grant, covering incidental costs associated with the program in accordance with Medicines Australia regulations. Sanofi Australia also provided financial support for the publication of this article. Vivacity Health (Viv Allen) provided editorial assistance in the development of this article, which was paid for by Sanofi, Australia. However, Sanofi Australia had no input into the content before or after submission. They were provided with a copy of the draft for their records before submission.

The authors would like to thank Vivacity Health for assistance for their ongoing contribution to the development and implementation of this program and for assisting in the preparation of this paper. The authors also recognize Sanofi Australia Pty Ltd for their continuing support and funding of this program.

For further information on this program, contact Viv Allen, Accredited Education Provider for RACGP [viv@vivacityhealth. com.au].
All named authors meet the International Committee of Medical Journal Editors (ICMJE) criteria for authorship for this manuscript, take responsibility for the integrity of the work as a whole, and have given final approval for the version to be published.

Disclosures. Gary Deed has received travel and research grants and/or speaker fees from Abbott, Astra-Zeneca, Becton Dickinson, Boehringer Ingelheim, Bristol Myers Squibb, Janssen, Lilly, Merck Sharp and Dohme, Novo-Nordisk, Novartis, Roche-Accuchek, Sanofi, and Takeda, companies licensing oral hypoglycaemic and insulin preparations/diabetes products in Australia.

Gary Kilov has received travel and research grants and/or speaker fees from Abbott, Astra-Zeneca, Boehringer Ingelheim, Bristol Myers Squibb, Janssen, Lilly, Merck Sharp and Dohme, Novo-Nordisk, Sanofi, and Takeda licensing oral hypoglycaemic and insulin preparations/diabetes products in Australia.

Patrick Phillips has received travel and research grants and/or speaker fees from Astra-Zeneca, Boehringer Ingelheim, Lilly, Merck Sharp and Dohme, and Sanofi licensing oral hypoglycaemic and insulin preparations in Australia.

Anita Sharma has received travel and research grants and/or speaker fees from Astra Zeneca, Boehringer Ingelheim, Lilly, Novo-Nordisk, Novartis, and Takeda licensing oral hypoglycaemic and insulin preparations/diabetes products in Australia.

Stephen Leow has received travel and research grants and/or speaker fees from Astra Zeneca, Boehringer Ingelheim, GSK, Lilly, and Novo Nordisk, licensing oral hypoglycaemic and insulin preparations/diabetes products in Australia. 
Ian Arthur has received travel and research grants and/or speaker fees from Sanofi licensing insulin preparations in Australia.

John Barlow has received travel and research grants and/or speaker fees from Astra-Zeneca, Becton Dickinson, Boehringer Ingelheim and GSK, Lilly, Merck Sharp and Dohme, Novo Nordisk, Novartis, and Sanofi licensing oral hypoglycaemic and insulin preparations/diabetes products in Australia.

Mark Kennedy has received travel and research grants and/or speaker fees from, Astra-Zeneca, Boehringer Ingelheim, Janssen, Lilly, Merck Sharp and Dohme, Novo Nordisk, and Sanofi licensing oral hypoglycaemic and insulin preparations/diabetes products in Australia.

Compliance with Ethics Guidelines. This article is based on previously conducted studies and does not involve any new studies of human or animal subjects performed by any of the authors. Permission was obtained from the de-identified survey participants.

Open Access. This article is distributed under the terms of the Creative Commons Attribution-NonCommercial 4.0 International License (http://creativecommons.org/licenses/ by-nc/4.0/), which permits any noncommercial use, distribution, and reproduction in any medium, provided you give appropriate credit to the original author(s) and the source, provide a link to the Creative Commons license, and indicate if changes were made.

\section{REFERENCES}

1. Britt H, Miller GC, Henderson J, Bayram C, Harrison C, Valenti L, Wong C, Gordon J, Pollack AJ, Pan Y, Charles J. General practice activity in Australia
2013-14. General practice series no. 36. Sydney: Sydney University Press; 2014. http://ses.library. usyd.edu.au/bitstream/2123/11882/4/978174332422 6_ONLINE.pdf.

2. Davis TM, Davis WA, Bruce DG. Glycaemic levels triggering intensification of therapy in type 2 diabetes in the community: the Freemantle Diabetes Study. Med J Aust. 2006;184:325-8.

3. Furler J, Spritzer O, Young D, Best J. Insulin in general practice. Barriers and enablers for timely initiation. Aust Fam Physician. 2011;40:617-21.

4. Colagiuri S, Dickinson S, Girgis S, Colagiuri R. National evidence based guideline for blood glucose control in type 2 diabetes, 2009. Canberra: Diabetes Australia and the NHMRC, Canberra; 2009. http:// static.diabetesaustralia.com.au/s/fileassets/diabetesaustralia/659c89a3-dcc2-4a2e-86e5-cc1d09956c60. pdf. Accessed Nov, 2015.

5. Diabetes management in general practice 2012/13. Guidelines for type 2 diabetes. Diabetes Australia. http://www.diabetesqld.org.au/media/98723/ diabetes_management.pdf. Accessed Nov, 2015.

6. National Prescribing Service. Early use of insulin and oral antidiabetic drugs. Prescribing Practice Review 40; 2008. http://www.nps.org.au/ publications/health-professional/medicinewisenews/2008/early-use-of-insulin-and-oralantidiabetic-drugs. Accessed Nov, 2015.

7. Phillips PJKISS. keep insulin safe and simple. Med Today. 2007;8(3):23-4.

8. Baker IDI Heart and Diabetes Institute. Diabetes: the silent pandemic and its impact on Australia; 2012. https://www.diabetesaustralia.com.au/Documents/ DA/What's\%20New/12.03.14\%20Diabetes\%20 management\%20booklet\%20FINAL.pdf. Accessed 18 Oct, 2014.

9. Australian Institute of Health and Welfare. Incidence of insulin-treated diabetes in Australia 2000-2009. Available from: http://www.aihw.gov. au/diabetes/incidence/. Accessed Oct 19, 2014.

10. The ADVANCE Collaborative Group. Intensive blood glucose control and vascular outcomes in patients with type 2 diabetes. $\mathrm{N}$ Engl J Med. 2008;358:2560-72.

11. Diabetes Australia. A National Diabetes Strategy and Action Plan 2013. https://static.diabetesaustralia.com. $\mathrm{au} / \mathrm{s} /$ fileassets/diabetes-australia/e549bdb8-0f80-46f8b827-35cb4f1b6cd2.pdf. Accessed Nov, 2015.

12. Phillips P. Insulin in type 2 diabetes: which to use and when. Med Today. 2010;11(7):50-62. 
13. Lillis S. The educational value of peer groups from a general practitioner perspective. J Prim Health Care. 2011;3:218-21.

14. Davis DA, Thomson MA, Oxman AD, Haynes RB. Changing physician performance. A systematic review of the effect of continuing medical education strategies. JAMA. 1995;274:700-5.

15. O'Brien MA, Rogers S, Jamtvedt G, Oxman AD, Odgaard-Jensen J, Kristoffersen DT, Forsetlund L, Bainbridge D, Freemantle N, Davis DA, Haynes RB, Harvey EL. Educational outreach visits: effects on professional practice and health care outcomes. Cochrane Database Syst Rev. 2007; Issue 4. Art. No.: CD000409.

16. Flodgren G, Parmelli E, Doumit G, Gattellari M, O'Brien MA, Grimshaw J, Eccles MP. Local opinion leaders: effects on professional practice and health care outcomes. Cochrane Database Syst Rev. 2011;Issue 8. Art. No.: CD000125.

17. Hammick M, Freeth D, Koppel I, Reeves S, Barr H. A best evidence systematic review of interprofessional education: BEME Guide no. 9. Med Teach. $2007 ; 29(8): 735-51$.
18. MacCathy D, Liza Kalistrom, Kadlec H, Hollander M. Improving primary care in British Columbia, Canada: evaluation of a peer-to-peer continuing education program for family physicians. BMC Med Educ. 2012;12:110.

19. Carroll JC, Rideout AL, Wilson BJ, et al. Genetic education for primary care providers. Improving attitudes, knowledge, and confidence. Can Fam Physician. 2009;55:e92-9.

20. Del Prato S, Felton AM, Munro N, Nesto R, Zimmet $P$, Zinman B. Improving glucose management: ten steps to get more patients with type 2 diabetes to glycaemic goal. Int J Clin Pract. 2005;59:1345-55.

21. Scott A, Jeon S-H, Joyce CM, et al. A randomised trial and economic evaluation of the effect of response mode on response rate, response bias, and item non-response in a survey of doctors. BMC Med Res Methodol. 2011;11:126. 